\title{
EXPLORING STREAM CHARACTERISTICS IN GAMING AUDIENCE WATCHING BEHAVIOR
}

*Taskin DIRSEHAN (Orcid ID: 0000-0002-3599-0951)

*Ahmet TOKLU (Orcid ID: 0000-0002-8053-7398)

*Dogukan EDIS (Orcid ID: 0000-0002-5369-7804)

*Mert USTUNDAG (Orcid ID: 0000-0002-9115-8713)

*Gulnur ONKOL (Orcid ID: 0000-0002-0680-7855)

*Marmara University, Turkey

\begin{abstract}
As the gaming concept becomes popular, people nowadays prefer not only to play games but also to watch others playing them. Although previous studies have attempted to reveal audience motivations to watch gaming content, their perspectives were on audience characteristics and streamer ones, but the stream basis has remained unexplored. To fill this gap, this study focused on the stream characteristics to understand gaming audience watching behavior. Four focus groups and five in-depth interviews revealed three main themes. The explored themes are (i) Stream Infrastructure for Streamers and Audience, (ii) Quality of the Stream Platform and (iii) Attractiveness of the Stream Platform. The results show that these unveiled themes are positively associated with the audience choice of consuming gaming content. Moreover, the companies should consider the stream characteristics to determine their communication strategies, such as sponsorship, advertising and/or public relations in the gaming world.
\end{abstract}

Keywords: Game Streaming Platform, Interactivity, Twitch, YouTube Live, Facebook Gaming

\section{INTRODUCTION}

Gaming is the fastest growing segment of the media and entertainment industry (CapitalGroup, 2019). Gamers spent approximately $\$ 150$ billion in 2019 on games, and they are expected to spend approximately $\$ 165$ billion in 2020 (Sanders, 2018). Moreover, the global gaming industry is expected to register a compound annual growth rate of 12\% during the forecast period 2020-2025 (PRNewswire, 2020). Thus, an increasing trend can be noticed in the gaming revenue.

Besides the consistent and impressive growth of the industry, the popularity of gaming video content has increased in recent years, already reaching more than 944 million people in 2019 with $\$ 6.5$ billion of market revenue generated (Statista, 2020a). This popularity is largely due to the emergence of dedicated video sharing platforms, such as Twitch, Facebook and YouTube Gaming, which are more specifically targeted to gaming video content and audiences.

The emergence of electronic sports (esports; competitive video gaming) has also had a significant impact on generating global awareness of gaming video content and has led to the rise of specific subgenres of video gaming content, such as "esports video content" (Taylor, 2012). Livestreaming platforms offer various benefits for advertising or sponsorship purposes during the stream. These ads generate revenue for the platform and streamers. For instance, a gaming company may sponsor a stream to promote gaming equipment (Zhao et al., 2018). For this reason, the game platforms compete with each other to attract more gaming audience.

In game streaming, streamers share video content of their ongoing games composited with a video feed of themselves. Streamers can chat with the audience and show their playing skills or experience simultaneously. Audiences in video games have more specific and centralized interests and knowledge of certain games than those in talent shows. Due to this similar interest and background, audiences in video game rooms are more likely to communicate actively and frequently (Törhönen et al., 2020).

A synergy rises when viewers actively participate in the streams. This increases the interaction, and the viewer puts himself/herself in the performer's shoes. This synergy leads to higher levels of emotional energy and greater involvement. A supporting work refers to the subject: "in the online streaming environment, viewers' emotional engagement is expanded to include the engagement with other fans as 
well as with the streamer" (Lim et al., 2020). The observational learning from a streamer, his/her mood and feelings elicited during the interaction with other audience members may also help users to develop an attachment to their favorite livestreaming channel. To have bonding relationships with a channel and to be a loyal audience member, emotional engagement is necessary (Sutton et al., 1997). Previous research showed that viewers' emotional engagement with other viewers and sports commentators during the live Olympic games led to channel loyalty (Weiss \& Schiele, 2013). In recent years, peer-to-peer internet streaming of games is a rapidly growing form of media (Sjöblom \& Hamari, 2017). Currently, game streaming has developed from a niche market into a mainstream activity (Sjöblom et al., 2019). Even though recent studies analyze the audience's reasons to watch streamers to play games (Hamari \& Sjöblom, 2017; Harpstead et al., 2019; Sjöblom \& Hamari, 2017; Xiao, 2020), the findings lie on audience characteristics i.e., cognitive, affective, personal integrative, social integrative and tension release motivations (Sjöblom \& Hamari, 2017) and on streamers' motivations to broadcast live streams i.e., intrinsic and extrinsic motivational forces (Zhao et al., 2018). However, the stream platforms' characteristics remain unexplored. To fill this gap, in this study, we tried to gain a better understanding on the roles of platforms in audience preferences of game watching.

\section{CHARACTERISTICS OF GAME STREAMING}

Traditionally, media have been classified as cool (requiring a higher degree of participation) and hot (requiring less participation (McLuhan, 1994).In terms of game streaming, Sjöblom and Hamari (2017) suggest the mix of media for a highly interactive experience where the video content represents the hot media and facilitating the interaction via the chat functionalities as cool media.

Twitch has become a leader for the streaming platform after its acquisition for $\$ 970$ million by Amazon in 2014 (Zhang \& Liu, 2015). With 9.36 billion of hours watched on the platform, the gaming video content consumption was dominated by Twitch in 2018. YouTube Live followed, with 2.31 billion of hours watched, and Microsoft's Mixer accounted for close to 168 million hours (Statista, 2020b). Facebook introduced "Facebook Gaming" to the market in 2018 (Segarra, 2018). According to a recent study conducted by Stream Hatchet-a Spain-based gaming and esports livestreaming analytics companyTwitch still held $66 \%$ of the total hours watched market share in July 2020 , even with a loss of $2.9 \%$ from the previous year. By stealing viewership from Twitch, YouTube reached more than 517 million hours watched. Following the Mixer shutdown in 2020, Facebook Gaming generated 280 million hours watched (Rothschild, 2020).

The focus of Mixer and Twitch is game streaming. However, social media platforms Facebook and YouTube launched new services to the game streaming market. On the other hand, Facebook is a new entrant, whereas Twitch and YouTube are existent in the market. Based on their business models, the major players in the market can be classified as in Figure 1.

\section{RESEARCH DESIGN}

To explore deeply the audience watching behavior based on the stream characteristics, we preferred to use qualitative research techniques in this study. Even though qualitative researches are limited in generalizability to larger groups (Neergaard \& Ulhøi, 2007), their goal is to gain insight and build theory (Bryman, 2016). As a qualitative technique, focus group methodology is an effective method for understanding young adults' lived experiences with technology (Krueger \& Casey, 2000; Vaterlaus et al., 2016). The use of focus groups provides an environment in which the participants can interact with each other and discuss the ideas that result in a wider range of responses on experiences (Hanna et al., 2018). Indepth semi-structured interviews with field experts followed the focus groups to increase the trustworthiness of the results, as suggested by Vaterlaus et al. (2016). In-depth interviews are efficient and provide depth of information (Palmerino, 1999; Priporas et al., 2017; Stokes \& Bergin, 2006).

\section{Sample Determination}

This research used a non-probability, purposive sampling method, enabling us to select participants appropriate to the purpose of the study (Hanna et al., 2018). This method has been used to reach good sources of data for the exploratory researches (Djafarova \& Rushworth, 2017; Easterby-Smith et al., 2018). Young adults who spend time watching game streams were recruited from Istanbul. 16 young adults (female, $\mathrm{n}=4$; male, $\mathrm{n}=12$ ) between the ages of 19 and 25 (mean age $=22.375$ ) were selected to participate in one of the four focus groups. The sample size was considered sufficient for the exploratory purpose of 
the study. The sample size was also large enough to draw useful evidence and small enough to enable effective analysis as suggested by Saunders et al. (2009). It met also the criteria set by Onwuegbuzie and Leech (2007) and De Ruyter and Scholl (1998) who recommend sample sizes of 15 to 20 and 15 to 40 respectively. The participants reported that their daily average playtime ranged between 1 and 10 hours $($ mean $=4.938)$, and their daily average watching time was ranged between 1 and $8($ mean $=2.125)$. The participants had annual game budgets ranged from $\$ 0$ to $\$ 250$ per year. Table 1 summarizes the descriptions.

After completing the focus group study, five in-depth interviews were conducted to validate the results. For this purpose, five experts in the field were invited to 50-60-minute in-depth interviews, and they were interviewed through an interview guide based on the existing literature (Burke, 2002). The first expert is one of the founders of Tier Gaming, a media for organizing tournaments and news sharing. He is a gamer who previously participated in professional sports tournaments and won awards. He organized PUBG, WolfTeam and League of Legends (LoL) tournaments for a year and a half and is an expert in organization and media.

The second expert is a popular LoL Twitch publisher and professional who played LoL. He is also a media expert regarding Twitch. He has close friendships with many of the major streamers in Twitch.

The third expert was included in the study because he is one of Turkey's best LoL announcers. He is an expert who has been an announcer and commentator for LoL leagues and major tournaments in Turkey. He is a gaming community leader with approximately half a million followers on Twitter. He owns a game shop.

The fourth expert owns a gaming agency and manages communication and partnerships between publishers and companies. Besides, he conducts academic studies on gaming and is a strict gamer.

The last expert is a movie and series actress, YouTube content producer and a Twitch streamer to an average of 1,000 viewers.

\section{Data Collection and Analysis}

A semi-structured interview guide was used in conducting focus groups and in-depth interviews. The discussion was flexible and open-ended, as suggested by McCracken (1988).

The focus groups and interviews were scheduled according to the participants' availability and terminated when the saturation is reached (i.e., when the ideas become repetitive and no new information is gathered) (Krueger \& Casey, 2000). Each focus group lasted 50-60 minutes and was moderated by a professional from a fieldwork company. At the end of each session, the recordings were transcribed verbatim.

Four focus groups and in-depth interviews were conducted online due to the COVID-19 pandemic. Despite the advantages of online focus groups, such as the removal of geographical constraints, some limitations occur, such as the computer skills of the respondents (Malhotra, 2007). However, this limitation was not applicable in this study because the research purpose was about gaming and the participants were selected based on their $t$ time spent watching the gaming streams. Consequently, it was assumed that the participants had enough computer skills.

Ethical guidelines were applied during the interviews, such as no harm, informed consent, anonymity and honesty (Allmark et al., 2009; Bryman, 2016). The participants were informed that their personal opinions were important for the research and that there was not an ideal correct or wrong answer. Based on the participants' consent, the focus groups were recorded to increase the accuracy of data collection (Priporas et al., 2017).

The collected data was analyzed through thematic analysis to identify, analyze and report patterns within the data (Braun \& Clarke, 2006; Priporas et al., 2017). As explained by Ryan and Bernard (2003), the data were processed into categories or themes (Mitic \& Kapoulas, 2012) and then divided into categories to be analyzed (Kapoulas et al., 2002). For this purpose, the researchers read the data independently and discussed commonalities in the highlighted words, and eight coding categories were determined. Then, three were revealed from the codes that were "reflective of more than one key thought" (Hsieh \& Shannon, 2005). 


\section{RESEARCH FINDINGS}

Participants detailed their stream platform watching behavior and identified the characteristics of the streams in watching the platforms. The coding categories' three major themes are included in Table 2 . The themes are entitled as (a) Stream Infrastructure for Streamers and Audience, (b) Quality of the Stream Platform and (c) Attractiveness of the Stream Platform. Participant numbers were provided together with their comments to add context.

\section{Stream Infrastructure for Streamers and Audience}

"Watching the same streamer is not the same in different stream platforms."

Unlike television shows or traditional live streams, gaming streaming platforms offer interaction with streamers. It gives a chance for audiences to communicate and have fun together with the streamer and the other people in the audiences. This seems to be the attraction point for the audiences, as indicated by one of our participants: "It makes me happy to watch what we love with like-minded people. The audience is all anonymous, but I can understand and communicate with them. As if they were all my friends."

In our focus groups, we observed that streamers' ability to communicate through chat means a great deal to their audience. Just streaming games does not seem to be the only thing that matters. One participant even said, "It is important to me that the streamer plays well, but if it does not entertain me with his conversation and chitchat, I will stop watching."

\section{Entertainment Infrastructure}

As we understand from the focus group study, everything in gaming streaming starts with having fun and spending some quality free time. What these platforms offer revolves around this factor. However, they do not have the power to affect what streamers offer to audiences. Consequently, it comes down to what streamers offer to their audiences aside from just playing the game.

We saw in our group interviews that audiences expect more than just gameplay streaming, they come to these platforms to have fun. One participant said, "The streamers I watch are usually people who follow trends and make humor through them. Humor is the most important part for me. I would like to laugh and have fun while watching the stream."

We observed that streamers taking the extra step in their work, role-playing, or getting into their streaming characters really entertained audiences. One of our participants said, "Apart from watching gaming streams, I follow streamers who perform various role-plays, theater and imitations. Because I watch streamers mostly for fun." They also enjoyed watching streamers' when they were doing role-plays and imitations.

\section{Content Infrastructure}

The quality of the content seems to be the biggest factor, influencing consistent viewer counts. It includes everything, starting from entertaining audiences and having conversations with them to teaching the audience the right ways to play.

Each streamer has its own characteristics and styles, and this drives audiences to watch people who match their tastes, characteristics and likes. We observed that, when audiences watch and like someone, they expect them to stick with their characteristics and keep up whatever they are doing. One of our participants stated, "Every streamer has a different style, and each creates the content of their own right. Sticking to this helps them build a certain community. But, I think the factors that makeup quality content are having fun and learning."

The audience likes to watch whatever is new in the gaming industry, but while doing so they seem to search for their favorite streamers playing these games. This may indicate that streamers should keep up with gaming trends to maintain their audiences. This seems to result in new and not boring content. As one of our participants said, "I think streamers must produce different contents to catch up the trends but without breaking his/her line. Because after a while, same content starts to get cliché and bores people."

\section{Interaction Infrastructure}

As it is in real-life interactions or watching television shows, being sincere and natural has a great impact on livestreaming. As gaming streaming usually is a one-man show, audiences can stop watching easily and switch to another streamer if they see insincerity or streamers acting unnatural. 
Being unnatural often seems disturbing, and people tend to leave when they feel uncomfortable. When asked how a streamer should act, one participant said, "I think the streamer should be sincere. When he/she is looking down on anyone he/she becomes repulsive."

We observed that big streamers' audiences like them because of the way they act and be. They love how natural their reactions are and how sincere their conversations are, whether it is chitchatting or talking with in-game friends. "A streamer must be sincere in order to rise to the top and be permanent on the platform. Everyone knows that the streamer is doing this for money. However, it is repulsive that he/she makes this feel, " said one of the participants about how important sincerity is while streaming.

According to our observations, the establishment of instant and anonymous communication through various channels alone is not sufficient for improvement of quality in the communication category. Our participants expected platforms to support the process of keeping the reactions between the streamer and the audience at the highest level during instant communication.

One of our participants said, "I love watching live streams more because making instant reactions gives us the opportunity to produce something with the streamer, and that makes live streams more intimate. And this makes me feel more valuable." At this point, the ability of the streamer to give instant reactions in line with the messages from the audience makes the stream more valuable and preferred because it makes the live stream more intimate according to the statement of our participant. Capabilities, such as the ability of viewers to show their messages on the air for a certain fee, to keep the instant reactions between streamers and viewers at the highest level can make platforms more attractive.

Because of our research, we can state that platforms that cannot keep the interaction at a high level remain in the background in the live stream. In this regard, according to our participant, there is a difference between YouTube, which has a livestream feature, and Twitch channels in the form of "I think YouTube is out of touch among band stream platforms. But for me, Twitch is at different level because it's a very interactive environment."

\section{Quality of the Stream Platform}

According to the answers we received from the participants, platform-specific differences can be observed and shaped by the participants. While investigating the shaping of the viewing preferences of any gaming stream, the platform quality core construct that fits the above context appeared. Because the answer to the question "What are the qualities and quantities that make the platform high quality in terms of gaming streams?" constitutes a feature that can shape the choice of watching streams, according to the answers we received from our participants.

\section{Easy to Use/User Friendly}

Developing digital technology creates an opportunity that enables complex processes and processes to be reflected rapidly to the end-user. However, we can observe that the end-user is not interested in complex processes and structures in watching live streams but in easily meeting their needs.

In this regard, the phrases voiced by our participant actually reveal the expectation of ease of use and userfriendly interface in watching streams: "Platform ease of use is very important. Facebook has many restrictions. The materials required for the audience to enter the stream are limited. So, it's not user friendly. "In fact, the power of the ease of use and the success of the interface influences which platform is chosen to watch streams.

The importance of ease of use and user friendliness in terms of the choice of the stream platform is another quote from our participant: "Interface and design are very important and should attract me. Facebook's interfaces, colors, accessibility, and font styles are pretty bad. But in the other hand, Twitch has simple, clear, understandable interface, it's very useful and accessible, you can easily access the content you want. I think familiarity creates belonging and is powerful. Also Twitch care very much about their audience." We can say that color, accessibility and fonts, which are the interface elements in the channels, are an important factor in the preference of the stream to be followed, apart from all the other elements we have mentioned.

In line with the aforementioned elements, we understand that the platform enables the viewers to see the platform in a form that can be watched by meeting the user friendliness expectations: "Layout, overlays, 
accessibility, diversity (category) -anonymity. These make the platform watchable, followable, and connectable."

\section{Quality of the Communication Channels}

According to the data we obtained from our participants, we can easily say that the viewers demand the blessings of instant data flow and being online on live stream platforms. The desire to communicate by giving instant feedback to the streamer who communicates with them also manifests itself in live stream platforms. This shows us that there is an expectation and even stipulation that the two-way asymmetric communication model, which is one of the communication models, will be implemented on streams platforms over the one-way symmetric communication model (Grunig \& Grunig, 1992).

In this context, one of our participants states that there should be an instant communication channel in the form of "It is very important that the chat provides material, I have to express myself as I wish." The desire to express herself/himself vividly reveals the necessity that she/he wants to be an active part of communication.

However, in addition to the expectation of instant communication channels on the platforms, the desire to participate anonymously in the communication process is among the responses we received from our participants. In this context, the inference that staying anonymous in the instant communication process makes the audience feel comfortable: "You communicate with the streamer via chat. Chat should meet my expectations and be able to express myself freely. And should offer anonymity, I have to feel comfortable."

\section{Attractiveness of the Stream Platform}

Creating loyalty in the digital world often seems challenging because there are so many alternatives out there from which to choose. Nevertheless, the challenge in the digital world comes from how easy it is to change platforms in just a matter of seconds. This seems to be one of the biggest challenges Gaming Streaming platforms must overcome.

People choose platforms based on what they bring to the table aside from the content. In our focus group interviews, one participant responded to what makes a platform watchable as "Layout, overlays, accessibility, diversity (category) -anonymity. These make the platform watchable, followable, and connectable."

Aside from platform loyalty, what are the key factors in loyalty correlation between streamers and audiences? What core factors drive the audience's attention, time and emotions toward creating loyalty?

In our research, we tried to find what creates loyalty toward streamers and platforms, how loyalty is created, and what the audience expects from the streamers/platforms.

\section{Platform Culture}

If we think of live stream platforms as television channels, the expectation of the audience from each television channel is different. Rather than the differences of the content offered by the channels, points such as differences in corporate lines and differences in communication languages are the points where television channels differ. According to the data we obtain from our participants, we can easily say that live stream platforms differ in similar ways for the audience.

One of our participants expressed the importance of the culture the platform creates with the communication language and jargon: "Platforms have a jargon and a language, this is about experience. Something that will occur over time. You cannot buy it with money, you cannot create a cult with money, and you cannot buy belonging with money. Platforms should make their audience to feel special and respond to their expectations to create 'belonging'." Stating that language and jargon naturally formed the platform culture over time, our participant stated she/he should be successful in making her audience "feel belonging" with this culture.

It is among the responses from our participants that, after a feeling of belonging, a habit of the platform culture developed. At this point, we see that the importance of the habit puts the change of the platform at the same level with the change of the district: "Platform culture is an important issue, when you change the neighborhood, you experience a cultural difference because of habituation." 
One of our participants expressed the fact that this platform habit can sometimes go beyond even the publishers they love: "You get used to the platforms, environment and culture. You don't want to quit and go. If the streamer you follow goes, you don't go, you discover another streamer and start watching him/her." When the place of belonging and habit of the platform culture occurs, it is seen as a sufficient reason for the audience to stay on the same platform, even if the streamer they watch is gone. Again, with the example of television, even if a favorite program or TV show is transferred to another TV channel, the loyal viewers may want to follow other programs or series on the same channel.

According to the answers we have obtained, expectations of "Ease of Use/User Friendliness," "Communication Channels," "Offering Interactions and Instant Reactions" and "Platform Culture" are special points that enable our participants to see a platform with high quality. It is vital that the perception of platform quality is settled with these qualities in terms of the streams that the audience will follow. Regardless of the content presented and the publisher, the expectation for platform quality has been quite well established on behalf of the audience and has emerged as requested.

\section{Consistency}

Our focus group interviews showed that consistency in streamers' schedules plays a huge role in audience loyalty. We observed in our interviews that the audiences have periods to watch streamers, whether it is in the morning with breakfast or in the evening with dinner. As one participant said, "There is a streamer that I watch as I have breakfast every morning when I wake up. He streams at the same time every morning, which keeps my commitment to him."

Matching periods with streamers include repeated watch times, more time to spend with audiences to bond, and more. If audiences can keep track of their favorite streamers' periods, they can anticipate their streaming times and organize their schedules according to the situation.

One of the participants stated, "Streamer's consistency is very important to me. Knowing when I can watch it keeps me going. So I must be able to predict when the streamer will start streaming. I don't like she/he if there is any inconsistency here." We saw that this situation is similar to spending time with your friends and making plans with them. We observed that streamer and audience loyalty is just like loyalty between friends and how it is created through spending time, laughing and enjoying free time together.

Our participants repeatedly stated that consistency results in more watch time and creating loyalty toward the streamer. If it gets harder to follow, audiences tend to find a new streamer to watch in their own time, which results in lost audiences over time.

\section{Daily Routine}

Many of our participants stated that their watching habits are based on daily routines. When they start idling, they turn their attention toward streaming platforms, such as Twitch or YouTube. When asked about the reasoning, one participant stated, "I go to YouTube every time I am idle but, I don't know the reason. Like getting up in the evening and stirring at a fridge. It has become a habit."

Streamers being there for the people when they are idling as part of their daily routines seems to be an important way to gain audience loyalty. The more people see streamers in their free time, the more interested they can get.

Aside from idling, people spend a lot of time in front of their computers, whether it is work-related or just spending free time. Therefore, it becomes a daily activity to open computers and occasionally search for some content to view in their free time. One of our participants gave an example: "Twitch automatically opens when I turn on my computer. I eat every meal in front of my computer. Like watching television, I watch streamers on Twitch."

\section{CONCLUSION}

With the development of technology, the gaming industry is currently receiving attention from academicians and practitioners to develop strategies. However, the research on gaming is still in its infancy, and there is a gap in the literature about the characteristics of the stream platforms. Some successful streamers make a strategic mistake and fail when they change stream platforms. The main reason for this failure depends on the difference in stream platform characteristics. The main purpose of this study was to explore stream characteristics in gaming audience watching behavior. For this exploratory purpose, a 
qualitative approach was preferred, and a focus group study was implemented to gather insights about the stream characteristics from the respondents as they watch gaming content. Three main themes were revealed as (i) Stream Infrastructure for Streamers and Audience, (ii) Quality of the Stream Platform and (iii) Attractiveness of the Stream Platform. Then, an in-depth interview research conducted with five experts in the gaming field validated the results.

The research evidence suggests that the success of streaming platforms depends on the audience-focus, and the stream characteristics are designed to improve the viewers' experiences. Current stream platforms, which aim to attract new viewers or sponsors and potential new entrants in the industry, should first provide an infrastructure for entertainment, content and interaction as main standards expected by the audience. Secondly, they need to provide a user-friendly platform, including communication channels with the streamer, such as chat boxes. Lastly, the streamer needs to be consistent to be watched in a daily routine, and they will be differentiated by creating a platform culture.

With its contribution to literature, this study has several limitations, specifically based on the qualitative nature of the research. As the results may be considered inputs for further quantitative studies such as scale development attempts, generalization of the current study's results should be done carefully.

\section{ACKNOWLEDGEMENT}

The authors gratefully acknowledge the Altyol Research Company-a professional fieldwork company located in Istanbul — for the helpful ideas and suggestions in improving the research instruments, in addition to their effort in professionally moderating and conducting the focus groups and in-depth interviews. 


\section{REFERENCES}

Allmark, P., Boote, J., Chambers, E., Clarke, A., McDonnell, A., Thompson, A., \& Tod, A. M. (2009). Ethical issues in the use of in-depth interviews: literature review and discussion. Research Ethics, 5(2), 48-54.

Braun, V., \& Clarke, V. (2006). Using thematic analysis in psychology. Qualitative research in psychology, 3(2), 77-101.

Bryman, A. (2016). Social research methods. Oxford university press.

Burke, R. (2002). Hybrid recommender systems: Survey and experiments. User modeling and useradapted interaction, 12(4), 331-370.

CapitalGroup. (2019). Video game industry goes for the win.

https://www.capitalgroup.com/europe/capitalideas/article/video-game-industry.html

De Ruyter, K., \& Scholl, N. (1998). Positioning qualitative market research: reflections from theory and practice. Qualitative market research: An international Journal.

Djafarova, E., \& Rushworth, C. (2017). Exploring the credibility of online celebrities' Instagram profiles in influencing the purchase decisions of young female users. Computers in Human Behavior, 68, 1-7.

Easterby-Smith, M., Thorpe, R., Jackson, P. R., \& Jaspersen, L. J. (2018). Management and business research. Sage.

Grunig, J. E., \& Grunig, L. A. (1992). Models of public relations and communication. Excellence in public relations and communication management, 1992, 285-325.

Hamari, J., \& Sjöblom, M. (2017). What is eSports and why do people watch it? Internet Research.

Hanna, P., Font, X., Scarles, C., Weeden, C., \& Harrison, C. (2018). Tourist destination marketing: From sustainability myopia to memorable experiences. Journal of destination marketing \& management, 9, 3643.

Harpstead, E., Rios, J. S., Seering, J., \& Hammer, J. (2019). Toward a Twitch Research Toolkit: A Systematic Review of Approaches to Research on Game Streaming. Proceedings of the Annual Symposium on Computer-Human Interaction in Play,

Hsieh, H.-F., \& Shannon, S. E. (2005). Three approaches to qualitative content analysis. Qualitative health research, 15(9), 1277-1288.

Kapoulas, A., Murphy, W., \& Ellis, N. (2002). Say hello, wave goodbye: missed opportunities for electronic relationship marketing within the financial services sector? The International Journal of Bank Marketing, 20(7), 302-310.

Krueger, R. A., \& Casey, M. A. (2000). Focus groups: A practical guide for applied research. Thousand Oaks, CA: Sage.

Lim, J. S., Choe, M.-J., Zhang, J., \& Noh, G.-Y. (2020). The role of wishful identification, emotional engagement, and parasocial relationships in repeated viewing of live-streaming games: A social cognitive theory perspective. Computers in Human Behavior, 106327.

Malhotra, N. (2007). Marketing research: An applied orientation (5th Edition ed.). Pearson Education, Inc.

McCracken, G. (1988). The long interview (Vol. 13). Sage.

McLuhan, M. (1994). Understanding media: The extensions of man. MIT press.

Mitic, M., \& Kapoulas, A. (2012). Understanding the role of social media in bank marketing. Marketing Intelligence \& Planning, 30(7), 668-686.

Neergaard, H., \& Ulhøi, J. P. (2007). Handbook of qualitative research methods in entrepreneurship.

Edward Elgar Publishing. 
Onwuegbuzie, A. J., \& Leech, N. L. (2007). A call for qualitative power analyses. Quality \& Quantity, 41(1), 105-121.

Palmerino, M. B. (1999). Take a quality approach to qualitative research. Marketing News, 33(12), 35-36.

Priporas, C.-V., Stylos, N., \& Fotiadis, A. K. (2017). Generation Z consumers' expectations of interactions in smart retailing: A future agenda. Computers in Human Behavior, 77, 374-381.

PRNewswire. (2020). Global Gaming Industry: Growth, Trends and Forecast 2020-2025.

https://www.prnewswire.com/news-releases/global-gaming-industry-growth-trends-and-forecast-20202025-301042773.html

Rothschild, J. (2020). YouTube stealing live streaming market share.

https://streamhatchet.com/2020/08/14/youtube-stealing-live-streaming-market-share/

Ryan, G. W., \& Bernard, H. R. (2003). Techniques to identify themes. Field methods, 15(1), 85-109.

Sanders, L. (2018). Germany's video game industry seeks help amid boom.

https://www.dw.com/en/germanys-video-game-industry-seeks-help-amid-boom/a-45234549

Saunders, M., Lewis, P., \& Thornhill, A. (2009). Research methods for business students. Pearson education.

Segarra, L. M. (2018). Facebook debuts new service to capitalize on growth in video games as a spectator sport. https://fortune.com/2018/06/08/facebook-game-streaming-platform/

Sjöblom, M., \& Hamari, J. (2017). Why do people watch others play video games? An empirical study on the motivations of Twitch users. Computers in Human Behavior, 75, 985-996.

Sjöblom, M., Törhönen, M., Hamari, J., \& Macey, J. (2019). The ingredients of Twitch streaming: Affordances of game streams. Computers in Human Behavior, 92, 20-28.

Statista. (2020a). Leading platforms for viewing gaming video content worldwide in 2019, by revenue share. https://www.statista.com/statistics/446060/gaming-video-content-platforms-revenue-share/

Statista. (2020b). Number of hours of gaming video content (GVC) viewed on selected streaming platforms worldwide in 2018. https://www.statista.com/statistics/962850/hours-viewed-gaming-streamplatforms/

Stokes, D., \& Bergin, R. (2006). Methodology or “methodolatry"? An evaluation of focus groups and depth interviews. Qualitative market research: An international Journal.

Sutton, W. A., McDonald, M. A., Milne, G. R., \& Cimperman, J. (1997). Creating and fostering fan identification in professional sports. Sport marketing quarterly, 6, 15-22.

Taylor, T. L. (2012). Raising the stakes: E-sports and the professionalization of computer gaming. Mit Press.

Törhönen, M., Sjöblom, M., Vahlo, J., \& Hamari, J. (2020). View, play and pay?-The relationship between consumption of gaming video content and video game playing and buying. Proceedings of the 53rd Hawaii International Conference on System Sciences,

Vaterlaus, J. M., Barnett, K., Roche, C., \& Young, J. A. (2016). "Snapchat is more personal": An exploratory study on Snapchat behaviors and young adult interpersonal relationships. Computers in Human Behavior, 62, 594-601.

Weiss, T., \& Schiele, S. (2013). Virtual worlds in competitive contexts: Analyzing eSports consumer needs. Electronic Markets, 23(4), 307-316.

Xiao, M. (2020). Factors influencing eSports viewership: An approach based on the theory of reasoned action. Communication \& Sport, 8(1), 92-122.

Zhang, C., \& Liu, J. (2015). On crowdsourced interactive live streaming: a twitch. tv-based measurement study. Proceedings of the 25th ACM Workshop on Network and Operating Systems Support for Digital Audio and Video, 
Zhao, Q., Chen, C.-D., Cheng, H.-W., \& Wang, J.-L. (2018). Determinants of live streamers' continuance broadcasting intentions on Twitch: A self-determination theory perspective. Telematics and Informatics, 35(2), 406-420. 


\section{Gaming-Focused Platform}

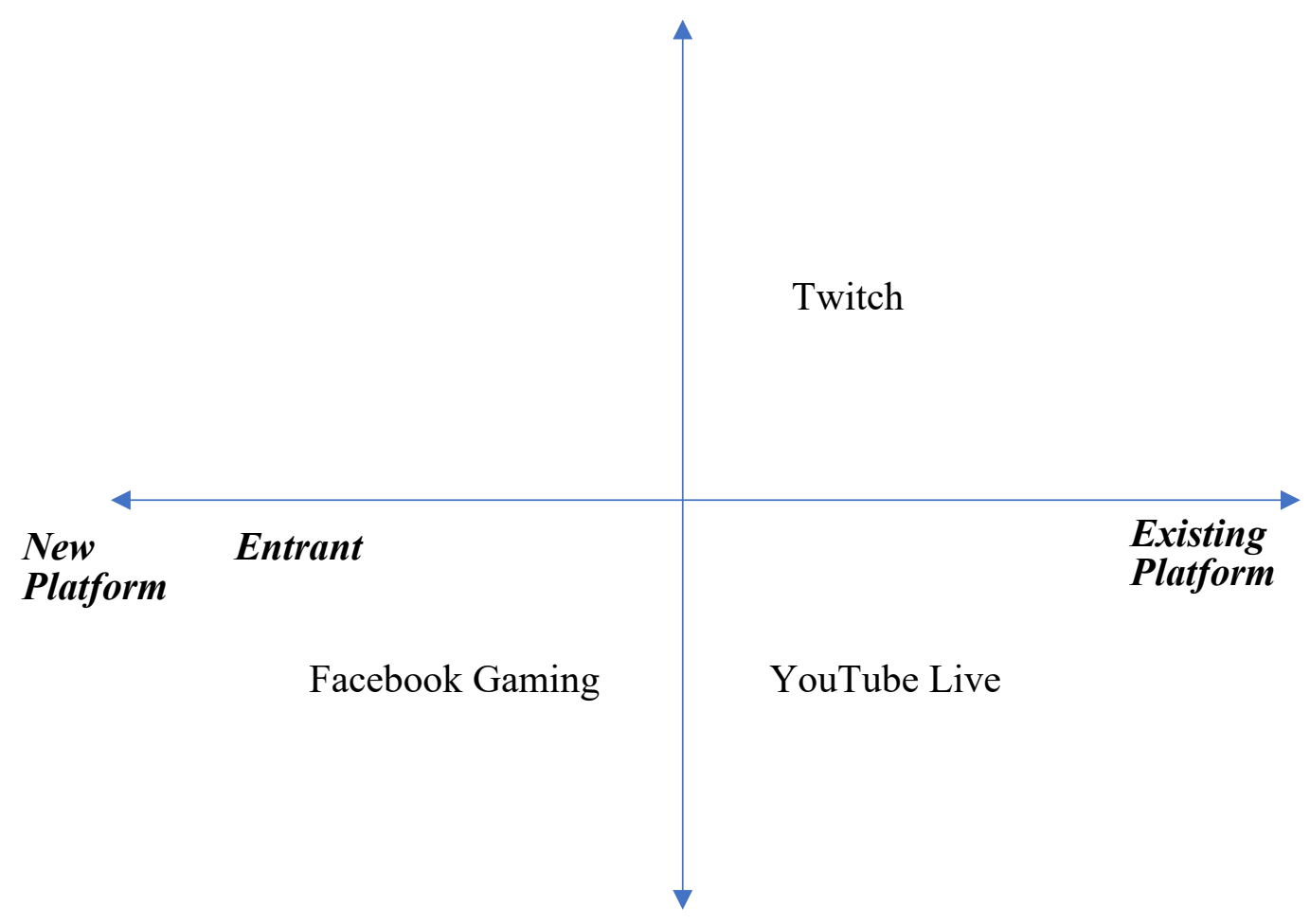

Fig.

Social Media Platform Introducing Game Streaming

Classification of Game Streaming Platforms

Source: Developed by the authors 
Journal of Global Strategic Management | V. 15 | N. 2 | 2021-December| isma.info | 133-146 | DOI: 10.20460/JGSM.2022.307

\section{APPENDIX. TABLES}

Table 1 Focus Group Participant Characteristics

\begin{tabular}{|c|c|c|c|c|c|c|}
\hline Groups & Participants & Age & Gender & $\begin{array}{l}\text { Daily Average } \\
\text { Play Time (h) }\end{array}$ & $\begin{array}{c}\text { Daily Average } \\
\text { Watching Time } \\
\text { (h) }\end{array}$ & $\begin{array}{c}\text { Annual Game } \\
\text { Budget (\$) }\end{array}$ \\
\hline \multirow{4}{*}{$1^{\text {st }}$ Group } & 1 & 22 & Male & 5 & 3 & 200 \\
\hline & 2 & 23 & Male & 5 & 3 & 200 \\
\hline & 3 & 24 & Male & 8 & 8 & 50 \\
\hline & 4 & 23 & Male & 3 & 4 & 10 \\
\hline \multirow{4}{*}{$2^{\text {nd }}$ Group } & 5 & 22 & Male & 4 & 1 & 10 \\
\hline & 6 & 22 & Male & 3 & 1 & 10 \\
\hline & 7 & 22 & Female & 5 & 2 & 200 \\
\hline & 8 & 24 & Male & 1 & 1 & 0 \\
\hline \multirow{4}{*}{$3^{\text {rd }}$ Group } & 9 & 22 & Male & 4 & 1 & 10 \\
\hline & 10 & 22 & Male & 3 & 1 & 10 \\
\hline & 11 & 22 & Female & 5 & 2 & 200 \\
\hline & 12 & 24 & Male & 1 & 1 & 0 \\
\hline \multirow{4}{*}{$4^{\text {th }}$ Group } & 13 & 19 & Female & 10 & 1 & 250 \\
\hline & 14 & 22 & Female & 6 & 2 & 50 \\
\hline & 15 & 25 & Male & 6 & 1 & 100 \\
\hline & 16 & 20 & Male & 10 & 2 & 150 \\
\hline
\end{tabular}


Table 2 Explored themes based on the qualitative research

\begin{tabular}{l|l}
\hline Explored Themes & Example Statements from the Participants \\
\hline Theme 1 Stream Infrastructure for Streamers and Audience \\
\hline $\begin{array}{l}\text { Entertainment } \\
\text { Infrastructure }\end{array}$ & $\begin{array}{l}\text { "The streamers I watch are usually people who follow trends and make humor through them. Humor is the } \\
\text { most important part for me. I would like to laugh and have fun while watching the stream." (Participant \#1) } \\
\text { "Amitations. Because I watch streamers mostly for fun." (Participant \#5) } \\
\text { "It is important to me that the streamer plays well, but if it does not entertain me with his conversation and } \\
\text { chitchat, I will stop watching." (Participant \#6) }\end{array}$ \\
\hline $\begin{array}{l}\text { Content } \\
\text { Infrastructure }\end{array}$ & $\begin{array}{l}\text { "I think streamers must produce different contents to catch up the trends but without breaking his/her line. } \\
\text { "Every streamer has a different style and each creates content of their own right. Sticking to this helps them } \\
\text { build a certain community. But I think the factors that make up quality content are having fun and learning." } \\
\text { (Participant \#8) } \\
\text { "Streamers are also content creators. They should not be thought of as people who just play games from } \\
\text { their seats. The reactions in that game, the style of playing the game, the different characters in the friend } \\
\text { group, etc. I think big streamers pay close attention to these in order to make quality content." (Participant } \\
\text { \#8) }\end{array}$ \\
\hline $\begin{array}{l}\text { "I think the streamer should be sincere. When he/she is looking down on anyone he/she becomes repulsive." } \\
\text { (Participant \#3) } \\
\text { "I love watching live streams more because making instant reactions gives us the oppurtunity to produce } \\
\text { something with the streamer, and that makes live streams more intimate. And this makes me feel more } \\
\text { valuable." (Participant \#2) } \\
\text { "I think YouTube is out of touch among band stream platforms. But for me, Twitch is at different level } \\
\text { because it's a very interactive environment." (Participant \#8) } \\
\text { "A streamer must be sincere in order to rise to the top and be permanent on the platform. Everyone knows } \\
\text { that the streamer is doing this for money. However, it is repulsive that he/she makes this feel." (Participant } \\
\# 4) \\
\text { "If a streamer is not sincere and I find out that they are doing their streams just for money, I will stop } \\
\text { watching that person." (Participant \#16) }\end{array}$ \\
\hline
\end{tabular}

Theme 2 Quality of the Stream Platform

\begin{tabular}{l|l}
\hline & $\begin{array}{l}\text { "Interface and design are very important and should attract me. Facebook’s interfaces, colors, accessibility, } \\
\text { and font styles are pretty bad. But on the other hand, Twitch has simple, clear, understandable interface, it's } \\
\text { very useful and accessible, you can easily access the content you want. I think familiarity creates belonging }\end{array}$ \\
$\begin{array}{l}\text { Easy to use/ } \\
\text { User friendly is powerful. Also, Twitch care very much about their audience." (Participant \#2) } \\
\text { "Platform ease of use is very important. Facebook has many restrictions. The materials required for the } \\
\text { audience to enter the stream are limited. So, it's not user friendly." (Participant \#4) } \\
\text { "Layout, overlays, accessibility, diversity (category), and anonymity, these make the platform watchable, } \\
\text { followable and connectable." (Participant \#7) }\end{array}$ \\
$\begin{array}{l}\text { Quality of } \\
\text { Communication } \\
\text { Channels }\end{array}$ & $\begin{array}{l}\text { "It is very important that the chat provides material, I have to express myself as I wish." (Participant \#3) } \\
\text { "Youself freely. And should offer anonymity, I have to feel comfortable." (Participant \#7) }\end{array}$ \\
\hline
\end{tabular}

Theme 3 Attractiveness of the Stream Platform

"Platform culture is an important issue; when you change the neighborhood, you experience a cultural difference either because there is a habituation." (Participant \#1)

"You get used to the platforms, environment and culture. You don't want to quit and go. If the streamer you

Platform Culture follow goes, you don't go; you discover another streamer and start watching him/her." (Participant \#7) "Platforms have a jargon and a language, this is about experience. Something that will occur over time. You cannot buy it with money, you cannot create a cult with money, and you cannot buy belonging with money. Platforms should make their audience feel special and respond to their expectations to create 'belonging'." (Participant \#8)

"Streamer's consistency is very important to me. Knowing when I can watch it keeps me going. So, I must be able to predict when the streamer will start streaming. I don't like it if there is any inconsistency here." (Participant \#4)

Consistency

"There is a streamer that I watch as I have breakfast every morning when I wake up. He streams at the same time every morning, which keeps my commitment to him. It is not good for a streamer to open his stream in irregular periods because it gets harder to follow." (Participant \#6)

"I go on YouTube every time I am idle, but I don't know the reason. Like getting up in the evening and stirring at a fridge. It has become a habit." (Participant \#1)

Daily Routine

"Twitch automatically opens when I turn on my computer. I eat every meal in front of my computer. Like watching television, I watch streamers on Twitch.” (Participant \#7) 
Journal of Global Strategic Management | V. 15 | N. 2 | 2021-December| isma.info | 133-146 | DOI: 10.20460/JGSM.2022.307 